\title{
Translational and Clinical Pharmacology Considerations in Drug Repurposing for X-linked Adrenoleukodystrophy-A Rare Peroxisomal Disorder
}

\author{
Julianne Tieu ${ }^{1}$, Siddhee Sahasrabudhe ${ }^{2}$, Paul Orchard ${ }^{2}$, James Cloyd ${ }^{2}$, and Reena Kartha ${ }^{2}$ \\ ${ }^{1}$ University of Minnesota Twin Cities \\ ${ }^{2}$ University of Minnesota
}

July 12,2021

\begin{abstract}
X-linked adrenoleukodystrophy (X-ALD) is an inherited, neurodegenerative rare disease that can result in devastating symptoms of blindness, gait disturbances, and spastic quadriparesis due to progressive demyelination. Typically, the disease progresses rapidly, causing death within the first decade of life. With limited treatments available, efforts to determine an effective therapy that can alter disease progression or mitigate symptoms have been undertaken for many years, particularly through drug repurposing. Repurposing has generally been guided through clinical experience and small trials. At this time, none of the drug candidates have been approved for use, which may be due, in part, to the lack of pharmacokinetic/pharmacodynamic $(\mathrm{PK} / \mathrm{PD})$ information on the repurposed medications in the target patient population. Greater consideration for the disease pathophysiology, drug pharmacology, and potential drug-target interactions, specifically at the site of action, would improve drug repurposing and facilitate development. Although there is a good understanding of X-ALD pathophysiology, the absence of information on drug targets, pharmacokinetics, and pharmacodynamics hinders the repurposing of drugs for this condition. Incorporating advanced translational and clinical pharmacological approaches in preclinical studies and early stages clinical trials will improve the success of repurposed drugs for X-ALD as well as other rare diseases.
\end{abstract}

\section{Hosted file}

cover letter.pdf available at https://authorea.com/users/425249/articles/530106translational-and-clinical-pharmacology-considerations-in-drug-repurposing-for-x-linkedadrenoleukodystrophy-a-rare-peroxisomal-disorder

\section{Hosted file}

Review Article FINAL .docx available at https://authorea.com/users/425249/articles/530106translational-and-clinical-pharmacology-considerations-in-drug-repurposing-for-x-linkedadrenoleukodystrophy-a-rare-peroxisomal-disorder

\section{Hosted file}

Table 1.docx available at https://authorea.com/users/425249/articles/530106translational-and-clinical-pharmacology-considerations-in-drug-repurposing-for-x-linkedadrenoleukodystrophy-a-rare-peroxisomal-disorder 

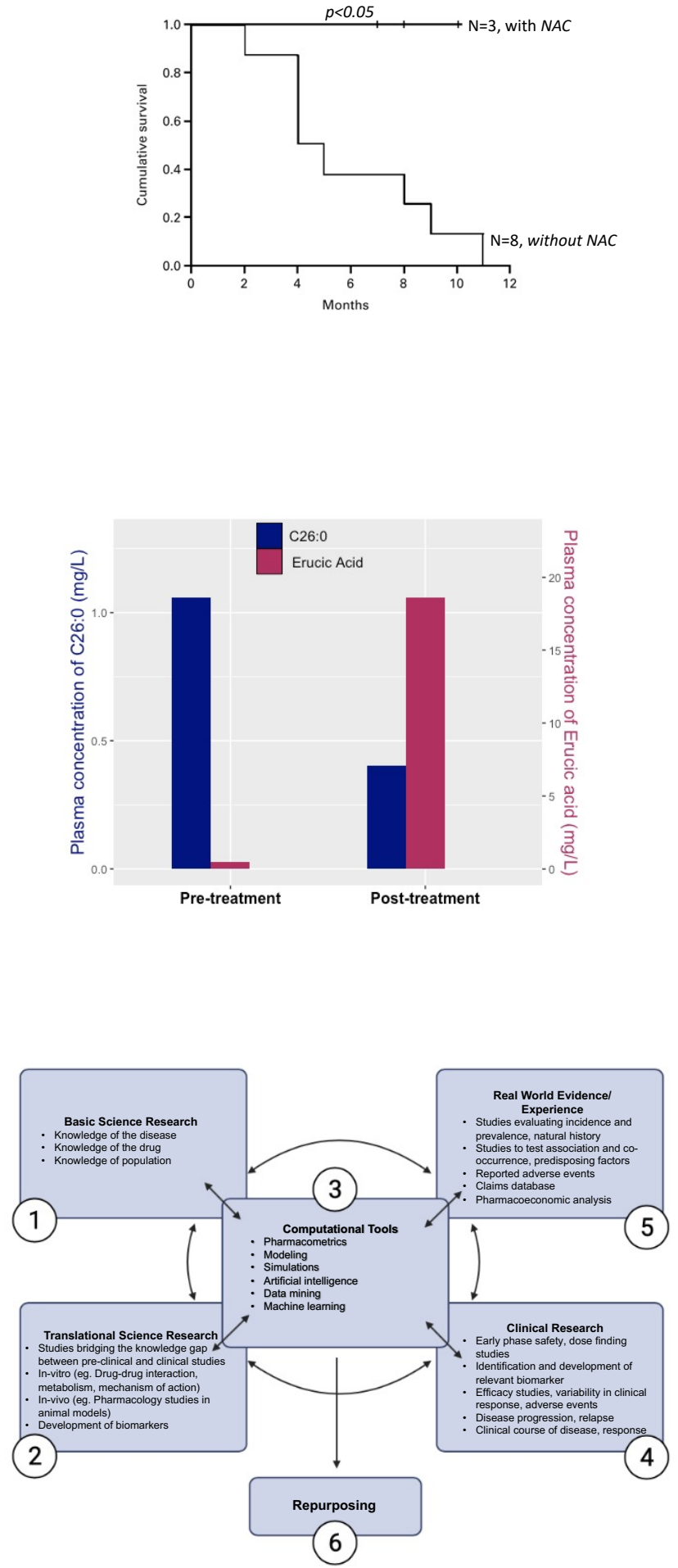